\title{
Morbidity and Mortality in Appendicitis in the Elderly
}

\author{
Hasan Calis
}

\begin{abstract}
Objective: To assess the factors affecting the morbidity and mortality in patients over 65 years of age who underwent appendectomy.

Study Design: An observational study.

Place and Duration of Study: Department of General Surgery, Faculty of Medicine, Ahi Evran University, Kirsehir, Turkey, from November 2014 to March 2017.

Methodology: Medical records of the patients over 65 years of age with the diagnosis of acute appendicitis who underwent appendectomy during the study period were retrospectively analyzed. Age and complications were noted. The reviewed outcome measures were perforation rates, morbidity and mortality.

Results: Three hundred and seventy-eight patients over 65 years of age presenting with abdominal pain were hospitalized for diagnosis and treatment. Appendectomy was performed in 112 patients. Laparoscopic appendectomy was performed in 70 of these patients. Perforation rate and morbidity were $40 \%$ and $28 \%$, respectively. There was no mortality.

Conclusion: Elderly patients show a high perforation rate and morbidity after appendectomy.
\end{abstract}

Key Words: Appendicitis, Morbidity, Elderly, Appendectomy.

\section{INTRODUCTION}

Appendectomy is one of the most common surgical procedures. ${ }^{1}$ The lifetime risk of developing appendicitis is higher in the second and third decades of life; it is $8.6 \%$ in males and $6.7 \%$ in females. ${ }^{2}$ While acute appendicitis is primarily a disease of the younger population, $5-10 \%$ of the cases occur in the elderly population. The probability of developing appendicitis is increasing with the increase in the average life expectancy. ${ }^{3}$

The diagnosis of appendicitis is primarily based on the history and physical examination. The differential diagnoses of acute appendicitis are significant. There may be a delay in diagnosis and treatment of elderly patients presenting with abdominal pain since they may have different clinical findings compared to those of younger patients. As a consequence, high morbidity and mortality can occur. 4 Prompt diagnosis and surgical referral will reduce the risk of perforation and prevent complications. Despite all these; in elderly patients, the risk of perforation due to appendicitis is up to $70 \%$ and the morbidity and mortality rates are $28-60 \%$ and $10 \%$, respectively. ${ }^{3}$ Therefore, an exact examination and avoidance of delayed diagnosis are highly important for morbidity and mortality.

Department of General Surgery, Faculty of Medicine, Alanya Alaaddin Keykubat University, 07400, Alanya, Turkey

Correspondence: Dr. Hasan Calis, Department of General

Surgery, Faculty of Medicine, Alanya Alaaddin Keykubat

University, 07400, Alanya, Turkey

E-mail:drhasancalis@hotmail.com

Received: January 09, 2018; Accepted: July 05, 2018
This study aimed to assess the factors affecting the patients over 65 years of age who underwent appendectomy.

\section{METHODOLOGY}

Medical records of the patients over 65 years of age admitted to Department of General Surgery, Faculty of Medicine, Ahi Evran University, Kirsehir, Turkey with the complaint of abdominal pain who underwent open or laparoscopic appendectomy with the diagnosis of acute appendicitis by one surgeon between November 2014 and March 2017, were retrospectively analyzed. Demographics, perioperative features, and postdischarge follow-ups were evaluated by analyzing patients' medical records. Based on these data, the complaints at admission, medical histories, the length of time from the onset of symptoms to hospital admission, comorbidities, physical examination findings, diagnostic laboratory and radiological tests, pathology reports and treatment modalities were reviewed. In addition, the lengths of hospital stays and morbidity and mortality rates of the patients were also recorded.

Patients undergoing appendectomy for reasons other than acute appendicitis and negative appendectomy were excluded from the study.

Data including demographics, medical history, diagnosis and treatment method as well as morbidity and mortality of the patients were recorded, and Microsoft Excel 2016 was used to analyze the descriptive statistics.

The work was performed in compliance with ethical standards and according to Institutional Review Board standards. This study was approved by Faculty of Medicine Clinical Research Ethical Committee, Ahi Evran University. 


\section{RESULTS}

During the 29-month period, 378 patients over 65 years of age presenting with abdominal pain were hospitalized for diagnosis and treatment. Among these, 112 (29.6\%) patients underwent appendectomy for the diagnosis of acute appendicitis, and laparoscopic appendectomy was performed in $70(62.5 \%)$ of these patients. The median follow-up of these patients undergoing appendectomy was 22 months. Sixty percent of the patients $(67$ patients) were males and $40 \%$ (45 patients) were females. The mean age of the patients was $70 \pm 7.1$ years and $40 \%$ of the patients (45 patients) had more than one comorbiditiy. The comorbidities are presented in Table I.

The mean duration of symptoms of patients was $8 \pm 2$ days and the median time from the onset of symptoms to hospital admission was 4 days, approximately two-thirds of the patients. Sixty-three percent of the patients (71 patients) had right lower quadrant pain and vomiting, while $21(18.7 \%)$ patients had only nausea. Diffuse

Table I: Comorbidities of patients with acute appendicitis.

\begin{tabular}{lc}
\hline Comorbidities & $\mathrm{n}(\%)$ \\
\hline Cardiac diseases & $17(15 \%)$ \\
Hypertension & $45(40 \%)$ \\
Bronchopulmonary diseases & $18(16 \%)$ \\
Renal diseases & $3(3 \%)$ \\
Diabetes mellitus & $16(14 \%)$ \\
\hline
\end{tabular}

Table II: Evaluation results of patients with acute appendicitis.

\begin{tabular}{lc}
\hline Time of study & 29 month \\
\hline Mean follow-up & 22 months \\
\hline Comorbidity $\mathrm{n}(\%)$ & $77(69 \%)$ \\
\hline Vomiting and pain right iliac fossa $\mathrm{n}(\%)$ & $71(63 \%)$ \\
\hline Diffuse abdominal pain $\mathrm{n}(\%)$ & $10(9 \%)$ \\
\hline Leukocytosis $\mathrm{n}(\%)$ & $56(50 \%)$ \\
\hline Leukopenia $\mathrm{n}(\%)$ & $16(14 \%)$ \\
\hline Fever $\mathrm{n}(\%)$ & $22(20 \%)$ \\
\hline Nausea $\mathrm{n}(\%)$ & $32(29 \%)$ \\
\hline Radiological evaluation $\mathrm{n}(\%)$ & $112(100 \%)$ \\
Abdominal ultrasonography & $112(100 \%)$ \\
Computerised tomography & $16(14 \%)$ \\
\hline Laparoscopy $\mathrm{n}(\%)$ & $70(63 \%)$ \\
\hline Laparotomy $\mathrm{n}(\%)$ & $42(37 \%)$ \\
Midline incision & $1(2 \%)$ \\
Mc Burney Incision & $41(98 \%)$ \\
\hline Perforation $\mathrm{n}(\%)$ & $45(40 \%)$ \\
\hline Localised abscess $\mathrm{n}(\%)$ & $35(31 \%)$ \\
\hline Diffuse abscess $\mathrm{n}(\%)$ & $9(8 \%)$ \\
\hline Complications $\mathrm{n}(\%)$ & $30(27 \%)$ \\
Wound infection & $22(20 \%)$ \\
$\quad$ Superficial & $18(16 \%)$ \\
Deep & $4(4 \%)$ \\
Pelvic abscess & $2(2 \%)$ \\
Incisional hernia & $2(2 \%)$ \\
Ileus & $1(2 \%)$ \\
Atelectasis & $2(2 \%)$ \\
Arrhythmias & $2(2 \%)$ \\
\hline
\end{tabular}

Table III: Causes of high morbidity.

Inflammation

Delay in hospital admission

Atypical clinical findings

Older age

Longer hospital stay

Longer antibiotic treatment

abdominal pain was present only in $9(8 \%)$ patients and these patients had diffuse purulent intra-abdominal fluid. Thirty-five patients had periappendicular, paracaecal or pelvic abscesses. All patients underwent abdominal ultrasonography, while $5(4 \%)$ patients with atypical clinical findings whose prediagnoses were considered to include diverticulitis and sigmoid colon tumor, additionally underwent abdominal computed tomography.

Pathology reports revealed perforation in $40 \%$ of the patients (45 patients). The length of time from the onset of symptoms to hospital admission of these patients was 8-10 days. According to histopathological examination, $29 \%$ of the patients (32 patients) had acute inflamed appendicitis, 26\% (29 patients) had gangrenous appendicitis, and $6 \%$ (7 patients) had plastron appendicitis. Laboratory results revealed leukocytosis in 50\% (56 patients) and leukopenia in $14 \%$ (16 patients) of the patients. Twenty percent of the patients (22 patients) had fever $\left(>38^{\circ} \mathrm{C}\right)$. Twenty-seven percent of the patients $(30$ patients) developed complications. All of these results are presented in Table II. Most of the morbidities were secondary to inflammation. The most important reasons for this were delay in hospital admission, atypical clinical findings, and older age (Table III).

The mean hospital stay was $2 \pm 1$ days for acute inflamed appendicitis, $4 \pm 2.1$ days for gangrenous appendicitis, and $10 \pm 3.2$ days for perforated appendicitis. Hospital stay was longer in patients with perforation and postoperative complications.

\section{DISCUSSION}

The diagnosis of acute appendicitis is more challenging in the elderly patients due to atypical clinical features, wide differential diagnosis, and difficulty in communication. ${ }^{4}$ As a result, perforation risk is higher in the elderly. In this study, perforation rate and morbidity rate were $40 \%$ and $28 \%$, respectively. Contrary to other studies, no mortality occurred in this study (Table II). The rate of perforation is around $20 \%$ in the general population while it is up to $70 \%$ in the elderly. ${ }^{5}$ This rate rises even higher with increasing age after 80 years. ${ }^{6}$ Forty percent of the patients had perforation in this and the time from the onset of complaints to hospital admission was 8-10 days in these patients.

While acute appendicitis is primarily a disease of the younger population, $5-10 \%$ of the cases occur in the elderly population. The probability of developing appendicitis is increasing with the increase in the 
average life expectancy. ${ }^{3}$ Of the 378 patients admitted to our clinic with abdominal pain, $30 \%$ were operated with the diagnosis of acute appendicitis. The lifetime risk of developing appendicitis is higher in the second and third decades of life and it is $8.6 \%$ in males and $6.7 \%$ in females. ${ }^{2}$ The rate of acute appendicitis in our patient group was high.

Elderly patients usually present with pain in the lower abdomen. However, right lower quadrant tenderness in clinical examination is not as common as that in younger adults. In addition, pain spreading from the periumbilical area to the right lower quadrant is not a common finding. ${ }^{7}$ The triad of right lower abdominal pain and tenderness, fever and leukocytosis was reported to be found in less than $26 \%$ of the patients over 60 years of age. 8 In this study, $63 \%$ of the patients (71 patients) had pain moving to the right lower quadrant and vomiting, while 32 patients had only nausea. Only 10 patients had diffuse abdominal pain in whole abdomen. Twenty percent of the patients had fever $\left(>38^{\circ} \mathrm{C}\right)$. Laboratory results revealed leukocytosis in $50 \%$ of the patients and leukopenia in $14 \%$.

Currently, there are no clear criteria defining the perforation risk related to acute appendicitis in elderly patients, while caution should be taken in the presence of sustained abdominal pain, fever over $38^{\circ} \mathrm{C}$, and leukocytosis. ${ }^{7,9}$ The mean duration of symptoms of the patients included in our study was $8 \pm 2$ days and the median time from the onset of symptoms to hospital admission was 4 days, approximately two-thirds of the patients. Forty percent of the patients had perforation and the time from the onset of complaints to hospital admission was 8-10 days in these patients.

The advances in the diagnosis and screening systems such as computed tomography and ultrasonography have increased the probability of correct diagnosis in patients with suspected appendicitis. ${ }^{8}$ Ultrasonography can generally provide the diagnosis of inflamed appendicitis and reveal free fluid findings in the pelvis, but this simple method is affected by the experience of the radiologist and the anatomy and compliance of the patient. In patients with suspected appendicitis, more extensive use of CT screening was demonstrated to improve diagnostic accuracy and decrease negative laparotomy rates.10,11 Recent studies reported a high sensitivity of $91-99 \%$ in this age group. 8 In a study, the incidence of perforation was reported to decrease from $72 \%$ to $51 \%$ during the last 20 years due to earlier use of CT. ${ }^{10}$ But, still ultrasound is the gold standard imaging method.

Diverticulitis, perforated caecum tumor, sigmoid colon tumor deviated to the right and gastroenteritis should be considered in the differential diagnosis of acute appendicitis in elderly patients. It is quite difficult to differentiate these diagnoses from acute appendicitis.
Abdominal computerized tomography is quite useful in elderly patients with both atypical clinical features and abdominal pain. In this study, five patients with atypical clinical findings whose prediagnoses were considered to include diverticulitis and sigmoid colon tumor, additionally underwent abdominal computed tomography. In all remaining patients, clinical examination was used together with abdominal ultrasonography and laboratory tests for diagnosis. The sensitivity and specificity of USG and CT was not calculated since only the positive cases were evaluated in this study. However, there were no false-positive results with CT scan.

In elderly patients, the risk of perforation due to appendicitis is up to $70 \%$ and the morbidity and mortality rates are $28-60 \%$ and $10 \%$, respectively. ${ }^{3}$ In this study, perforation rate and morbidity rate were $40 \%$ and $28 \%$, respectively. Contrary to other studies, no mortality occurred in this study (Table II). Most of the morbidities were secondary to inflammation. The most important reasons for this was likely to be delay in hospital admission, atypical clinical findings and older age of the studied cohort. Moreover, hospital stay is generally longer in elderly patients. This is generally caused by high complication rates, the need for a long antibiotic treatment, treatment of other comorbidities, and communication difficulties. ${ }^{12-15}$ As a result, hospital stay was longer in patients with perforation and morbidities.

\section{CONCLUSION}

Nowadays, more elderly patients with appendicitis are encountered due to increase in life expectancy. There may be a delay in diagnosis and treatment of elderly appendicitis since they may have different clinical findings. Mortality and morbidity are high. The main reasons for this situation may be delay in hospital admission, atypical clinical findings, older age, communication problems, and the need for longer hospital stays. Due to these reasons, elderly patients presenting with abdominal pain should be primarily assessed for acute appendicitis as well as the other possible reasons for acute abdomen, preferably with CT scan. Prompt diagnosis and surgical referral will reduce the risk of perforation and prevent complications.

\section{REFERENCES}

1. Nsar AR, Niazi S, Soomro AA. Diagnostic accuracy of serum C-reactive protein levels for the diagnosis of acute appendicitis. Pak J Med Health Sci 2017; 11:441-3.

2. Addiss DG, Shaffer N, Fowler BS. The epidemiology of appendicitis and appendectomy in the United States. Am J Epidemiol 1990; 132:910-25.

3. Frantz MG, Norman J, Fabri PJ. Increased morbidity of appendicitis with advancing age. Am Surg 1995; 61:40-4.

4. Jalil A, Shah SA, Saaiq M, Zubair M, Riaz U, Habib Y. Alvarado scoring system in prediction of acute appendicitis. J Coll Physicians Surg Pak 2011; 21:753-5. 
5. Sheu BF, Chiu TE, Chen JC. Risk factors associated with perforated appendicitis in elderly patients presenting with signs and symptoms of acute appendicitis. ANZ J Surg 2007; 77: 662-6.

6. Young YR, Chiu TE, Chen JC. Acute appendicitis in the octogenarians and beyond: a comparison with younger geriatric patients. Am J Med Sci 2007; 334:255-9.

7. Abou-Nukta F, Bakhos C, Arroyo K. Effects on delaying appendectomy for acute appendicitis for 12 to 24 hours. Arch Surg 2006; 141:504-6.

8. Pooler BD, Lawrence EM, Pickhardt PJ. MDCT for suspected appendicitis in the elderly: diagnostic performance and patient outcome. Emerg Radio 2012; 19:27-33.

9. Saaiq $M$, Din NU, Jalil A, Zubair M, Shah SA. Diagnostic accuracy of leukocytosis in prediction of acute appendicitis. J Coll Physicians Surg Pak 2014; 24:67-9.

10. Storm-Dickerson TL, Horattas MC. What we have learned over the past 20 years about appendicitis in the elderly? Am J Surg 2003; 185:198-201.

11. Gardner CS, Jaffe TA, Nelson RC. Impact of CT in elderly patients presenting to the emergency department with acute abdominal pain. Abdom Imaging 2015; 40:2877-82.

12. Kirstein B, Perry ZH, Mizrahi S, Lantsberg L. Value of laparoscopic appendectomy in the elderly patient. World $\mathrm{J}$ Surg 2009; 5:918-22.

13. Omari AH, Khammash MR, Qasaimeh GR. Acute appendicitis in the elderly: Risk factors for perforation. World J Emerg Surg 2014; 9:6.

14. Papandria D, Goldstein SD, Rhee D. Risk of perforation increases with delay in recognition and surgery for acute appendicitis. J Surg Res 2013; 184:723-9.

15. Salahuddin O, Malik MAN, Sajid MA, Azhar M, Dilawar O, Salahuddin A. Acute appendicitis in the elderly; Pakistan Ordnance Factories Hospital, Wah Cantt: Experience. J Pak Med Assoc 2012; 62:946-9.

.......... 